\title{
Awake ECMO and mobilizing patients on ECMO
}

\author{
Jumana Yusuf Haji ${ }^{1}$ (D) Sanyam Mehra ${ }^{1} \cdot$ Prakash Doraiswamy $^{1}$ \\ Received: 17 June 2020 / Revised: 6 October 2020 / Accepted: 9 October 2020 / Published online: 18 January 2021 \\ (C) Indian Association of Cardiovascular-Thoracic Surgeons 2021
}

\begin{abstract}
Extracorporeal membrane oxygenation (ECMO) is a lifesaving technology in critically ill patients who present with cardiac/ pulmonary/combined cardiopulmonary failure. These patients are the sickest of all patients in any critical care unit and will invariably have a prolonged course and rehabilitation. Spontaneous breathing and early mobilization can reduce the intensive care unit (ICU)-acquired weakness, improve functional recovery, and reduce superadded infections and length of stay in the hospital, thus decreasing the cost of treatment. In low socioeconomic countries, there is an associated challenge of the availability of specially trained personnel necessary to manage patients on ECMO. Managing and ambulating an awake patient on ECMO is very labour-intensive and poses various challenges. Every ECMO program should aim to develop goals, methods, and protocols to this end. These can be derived from best practices worldwide by suitably adapting to available personnel and equipment. In this review, we aim to highlight the advantages and associated challenges of awake ECMO and describe protocols to aid safe ambulation and physiotherapy for ECMO patients.
\end{abstract}

Keywords Awake ECMO · Safe ambulation on ECMO - Physiotherapy on ECMO

\section{Introduction}

Extracorporeal membrane oxygenation (ECMO) is an extracorporeal life support used in acute cardiac, pulmonary, or cardiopulmonary failure patients who have failed conventional treatment. Commonly ECMO is offered to critically ill patients. There is a tendency to continue the conventional intensive care unit (ICU) treatment protocols (ventilation, neuromuscular blocking agents (NMBAs), prone ventilation, deep sedation, inotropes) even after initiation of ECMO. The basic principle of ECMO is to rest the diseased organ, and hence, mechanical ventilation and inotropic support should be weaned early. Awakening these patients and managing issues

Jumana Yusuf Haji

drjyhaji@gmail.com; http://www.asterbangalore.com

Sanyam Mehra

sanyam.mehra07@gmail.com

Prakash Doraiswamy

prakash.doraiswamy@yahoo.com

1 Aster CMI Hospital Bangalore, 43/2, New Airport Road, NH.7, Sahakara Nagar, Bengaluru, Karnataka 560092, India like critical illness myopathy and neuropathy should also take priority, as this can hugely impact the post-ECMO course.

The purpose of this review is to highlight the advantages of awake and ambulatory ECMO, partially or entirely independent of mechanical ventilation. This article explores awakening and ambulating a patient on ECMO to maintain respiratory and skeletal muscle strength. Schweickert et al. studied the benefits of early physiotherapy in 104 critically ill patients in a randomized controlled trial. They concluded that a strategy for early physical and occupational therapy was safe and welltolerated. It resulted in better functional outcomes at hospital discharge, reduced ICU delirium, and ventilator-free days as compared with standard care [1]. Resultant shortening of the length of stay reduces healthcare costs and incidence of postICU care syndrome [2].

\section{Awake ECMO}

Awake ECMO is ECMO without mechanical ventilation in spontaneously breathing patients. These patients are maintained awake through the ECMO run [3]. Many centres in India are still in the early stage of gaining experience with ECMO. They have reasonable experience with mechanical 
ventilation for acute respiratory distress syndrome (ARDS). ECMO is an attractive option to prevent barotrauma and volutrauma of mechanical ventilation. However, this is only possible in dedicated centres in a highly select group of patients. Post ECMO initiation, there are several advantages of a spontaneously breathing patient such as reduction in ventilation-perfusion (V/Q) mismatch, better preservation of tone of respiratory muscles, and diaphragm, which maintains the functional residual capacity (FRC). The negative pressure during the inspiratory phase of a spontaneous breath improves venous return and cardiac filling and favours lymphatic drainage. The challenge is in understanding the heart-lung ECMO system interaction in a spontaneously breathing patient [4] (Table 1). Maintaining a patient awake on ECMO necessitates careful patient selection, cannulation considerations, sedation, and individualized planning of airway (extubation on ECMO, tracheostomy on ECMO).

\section{Patient selection}

There is a wide variation in the clinical condition of patients at presentation. The patient's level of consciousness, oxygen requirement $\left(\mathrm{PaO}_{2} / \mathrm{FiO}_{2}\right.$ ratio), positive end-expiratory pressure (PEEP) requirement, inotrope requirement, and comorbid conditions like obesity and continuous positive airway pressure (CPAP) dependence are of primary concern. These patient factors determine the timing, ease, and speed of initiation, i.e. feasibility of awake ECMO. The rationale to start ECMO in ARDS is to avoid detrimental effects of ventilatorinduced lung injury (VILI) [5, 6]. Additionally, awake ECMO is a way to prevent ventilator-associated pneumonia (VAP) and preserve the tone of respiratory muscles and diaphragm.

Patients needing venovenous (VV) ECMO for ARDS will invariably receive mechanical ventilation as the first line of therapy; however, a few centres offer VV ECMO as the first option [7]. Awake ECMO has worked as an alternative to mechanical ventilation in asthmatics [8] and Pneumocystis carinii pneumonia [9], and as a useful weaning strategy after severe postoperative ARDS, to shorten the duration of mechanical ventilation [10].

The prognosis in patients with cardiogenic shock, who are candidates for mechanical circulatory support, is very guarded unless being considered for early ECMO. These patients are suitable candidates for awake ECMO before the onset of secondary respiratory failure. Patients with cardiac failure (secondary to perioperative myocardial infarction (MI) [11], refractory arrhythmias, cardiotoxic drugs, aluminium phosphide poisoning) stabilized with venoarterial (VA) ECMO should be awakened and considered for early extubation. Extubation helps to offset the detrimental haemodynamic

Table 1 Advantages of spontaneous breathing and ambulation awake ECMO challenges faced and overcoming the challenges

\section{Advantages of awake spontaneously breathing patient Challenges of awake patient-ECMO system inter- Overcoming the challenges action} Better tone of respiratory muscles and diaphragm
improves functional residual capacity

Less V/Q mismatch

Negative pressure during inspiration improves venous return and favours lymphatic drainage

Reduces chances of VAP

Increased comfort

Improved delivery of inhalational medicines

Patient engagement in spirometry

Facilitation of physical rehabilitation

Facilitation of patient communication

Participation in decision-making

Lesser ICU psychosis
High work of breathing which may increase oxygen May need to deepen sedation to prevent demand and $\mathrm{CO}_{2}$ production

Transpulmonary pressure may be high leading to spontaneous induced lung injury (P-SILI)

Difficulty in monitoring ventilation and airway pressures

Interference with ECMO flow due to collapse in IVC over cannula during deep inspiration which causes chattering

Decreased clearance of secretions

ECMO $\mathrm{CO}_{2}$ removal may blunt patients spontaneous drive and this could lead to re-adsorption atelectasis

Equipment failure may be catastrophic as patient more ECMO dependent

Monitoring lines and managing an awake patient

Needs to be kept engaged

Maybe difficult to withdraw if the native organ does not improve

\section{fatigue}

Change from ETT to tracheostomy for better tolerance

Adjust sweep gas to balance respiratory drive (with caution)

Choose tracheostomy over extubation

Sedate if the respiratory effort is too much

Adjust ECMO flows (avoid higher flows than needed)

Correct hypovolaemia if that is causing the chattering

Choose tracheostomy over extubation if better lung toileting needed

Adjust sweep gas to avoid hypocapnia

Engage patient in breathing exercises

Keep everything ready for emergency intubation / resuscitation

Needs 1:1 nursing for monitoring and 2:1 while mobilizing

Books music television

Keep family involved in care 
effects of mechanical ventilation and the risks of VILI and VAP. Awake VA ECMO in patients presenting with acute on chronic heart failure works as a means for assessing patients suitable for ventricular assist devices (VADs) while temporarily supporting biventricular functions. Awake ECMO may thus help to stabilize end-organ functions, downgrade the disease for better outcomes, or work as a bridge to heart transplant $[12,13]$.

Few patients initiated on VV ECMO may need prolonged care to allow the native lung to recover [14]. They may become impossible to wean due to irreversible organ damage and may need bridging to lung transplant. ECMO as a bridge to lung transplant is extensively studied. Comparing patients bridged to lung transplant with awake ECMO versus mechanical ventilation, awake ECMO patients showed better outcomes due to shorter postoperative mechanical ventilation, and hence shorter length of hospitalization. Bridging with awake ECMO results in better tolerance of physical therapy, avoidance of VAP, and VILI, which could otherwise lead to multiorgan failure (MOF) and make the candidates unsuitable for a lung transplant $[15,16]$.

\section{Cannulation considerations (Table 2)}

The success of awake ECMO depends on the cannulation strategy and configuration of ECMO. It is suitable only for peripheral VA and VV ECMO. Awake ECMO works best when initiated in the ICU with percutaneous techniques under mild sedation and analgesia. Patients who are on mechanical ventilation too benefit from bedside cannulation techniques, as they are too unstable to be shifted to operation theatre or Cath lab for ECMO initiation. Some cannulation techniques require surgical intervention, shift to operation theatre (OT), and deep sedation/general anaesthesia (GA). Such complex procedures for peripheral ECMO must be employed after a careful risk-benefit analysis.

A double-lumen single cannula, for instance, is preferred by centres that routinely mobilize patients on venovenous ECMO as it may give freedom from groin cannulae (Fig. 1). However, this needs expertise as it is technically challenging. Deep sedation/anaesthesia and insertion in OT may be necessary as they are larger cannulae which require transesophageal echocardiography (TEE) guidance and imaging for correct positioning. Displacement could be disastrous as even slight changes in position could lead to massive flow fluctuations and recirculation. Hence, standard conventional cannulae may be safer and simpler to insert than double-lumen cannulae [17].

The conventional cannulation strategies for peripheral VV and VA ECMO involve the use of at least one femoral cannula. The standard access venous cannula is wire-reinforced and long. Hence, it is not at any risk of kinking (unless kinked during insertion) or slipping out as its inserted length is at least $35-45 \mathrm{~cm}$ to reach the diaphragm at the inferior vena cavaright atrium (IVC-RA) junction. The return cannula is short and can be more prone to accidental decannulation.

Table 2 Ambulation during awake ECMO — pros and cons of cannulation strategies

\begin{tabular}{|c|c|c|c|}
\hline \multirow{2}{*}{$\begin{array}{l}\text { Strategy for awake } \\
\text { ECMO and mobilization }\end{array}$} & \multicolumn{3}{|l|}{ Cannulation } \\
\hline & Site & Advantage & Disadvantage \\
\hline \multirow[t]{2}{*}{ Venovenous } & Femoral vein-internal jugular vein & $\begin{array}{l}\text { Possible under local/mild sedation } \\
\text { as technically easy } \\
\text { Ultrasound and transthoracic echo } \\
\text { (TTE) guided } \\
\text { Percutaneous, Seldinger's/semi-open } \\
\text { technique } \\
\text { Insertion in ICU possible }\end{array}$ & $\begin{array}{l}\text { Two cannulas to anchor safely } \\
\text { Need of at least one groin cannula }\end{array}$ \\
\hline & $\begin{array}{l}\text { Double-lumen single cannula-internal } \\
\text { jugular vein }\end{array}$ & $\begin{array}{l}\text { Single cannula to anchor } \\
\text { No groin cannula }\end{array}$ & $\begin{array}{l}\text { Needs expertise as technically difficult } \\
\text { Imaging and transesophageal ECHO } \\
\text { (TEE) guidance } \\
\text { Deep sedation as larger cannula } \\
\text { Insertion in OT/Cath lab preferred }\end{array}$ \\
\hline \multirow[t]{2}{*}{ Venoarterial } & Femoral vein-femoral artery & $\begin{array}{l}\text { Possible under local/mild sedation } \\
\text { as technically easy } \\
\text { Ultrasound and transthoracic echo } \\
\text { (TTE) guided } \\
\text { Seldinger's or semi-open technique } \\
\text { Insertion in ICU possible }\end{array}$ & $\begin{array}{l}\text { Two cannulas to anchor safely } \\
\text { Both cannulas in the groin }\end{array}$ \\
\hline & Femoral vein-axillary artery & $\begin{array}{l}\text { More comfortable as single cannula } \\
\text { in the groin }\end{array}$ & $\begin{array}{l}\text { Needs expertise } \\
\text { Deep sedation/general anaesthesia } \\
\text { Insertion in OT needed }\end{array}$ \\
\hline
\end{tabular}




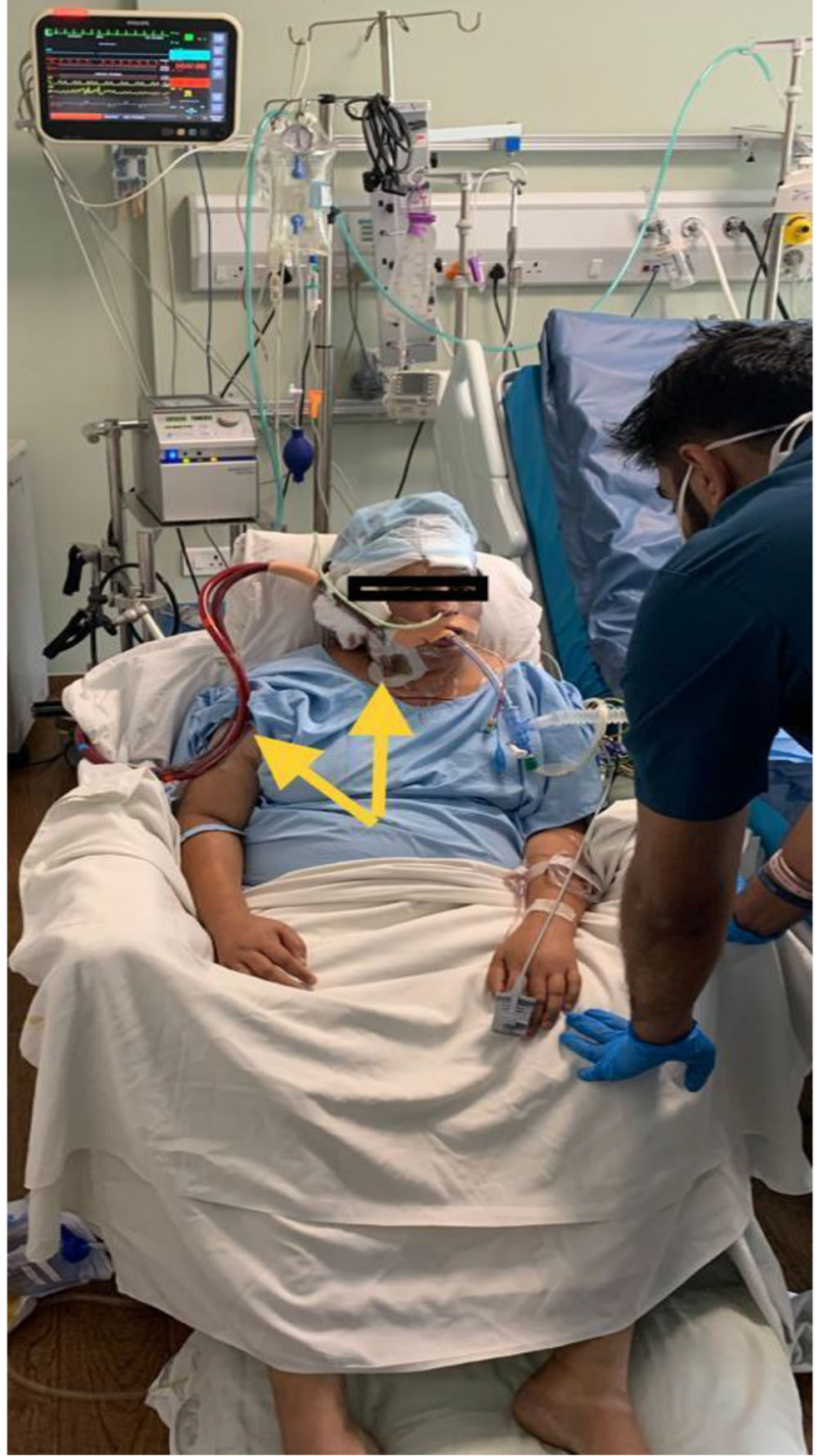

Fig. 1 A patient comfortably sitting out in a recliner while on ETT and VV ECMO. Yellow arrows, double-lumen VV cannula anchored securely to the arm and head

Venovenous return cannula is usually placed in the neck via the internal jugular vein (IJV) using Seldinger's technique and anchored to the head with headbands (Fig. 2a, b). Venoarterial return cannula can be either in the femoral artery or in the axillary artery. The femoral cannulae are easy to insert with ultrasound (USG) guidance and Seldinger's or semi-open technique under mild sedation. The arterial cannula is with a distal reperfusion cannula, and though it is short, it is anchored well in a loop with the distal cannula (Fig. 3a) Axillary artery return cannula may have better comfort for mobilization, but it needs surgical technique, hence deep anaesthesia and insertion in OT.

All cannulae need secure anchoring with no drag. The length of the tubings should be more than the patient's height for neck cannulae to allow the patient to stand (mobilization out of bed). The limb cannulae should be sutured and taped at intervals to prevent tugging or movement at the insertion site (Fig. 3b).

\section{Sedation plan (Table 3)}

The sedation plan must include techniques and drugs to achieve conscious sedation and comfort to allow for physiotherapy and mobilization. The sedation plan is usually guided by length on ECMO and goals achieved after ECMO initiation. At initiation, in an intubated and ventilated patient, it is preferable to continue heavy sedation, including NMBAs, as necessary for the first $24 \mathrm{~h}$. Propofol and fentanyl infusions, usually at higher doses, may be needed [18]. Midazolam and atracurium administered as intermittent bolus doses and titrated to achieve the ECMO goals are generally preferred. The priority in VV ECMO is to set achievable ECMO goals with appropriate ventilator settings, before awakening the patient. Spontaneous breathing causes the collapse of IVC due to negative intrathoracic pressure, sometimes leading to chattering, which may be mistaken for hypovolaemia. Thus, initially controlled ventilation is better to determine optimal flows and fluid boluses needed to achieve ECMO goals (Table 1). The priority in VA ECMO is to wean off inotropes and determine the flow requirements required. Patients with extensive atelectasis, consolidation, septic shock, or combined cardiorespiratory failure should be continued on mechanical ventilation for more extended periods as needed.
Fig. 2 a, b Neck internal jugular vein cannula in venovenous ECMO secured like a headband with transparent tape to the neck forehead and cap and shoulder. This prevents tugging and keeps the cannula secure during head and neck movements

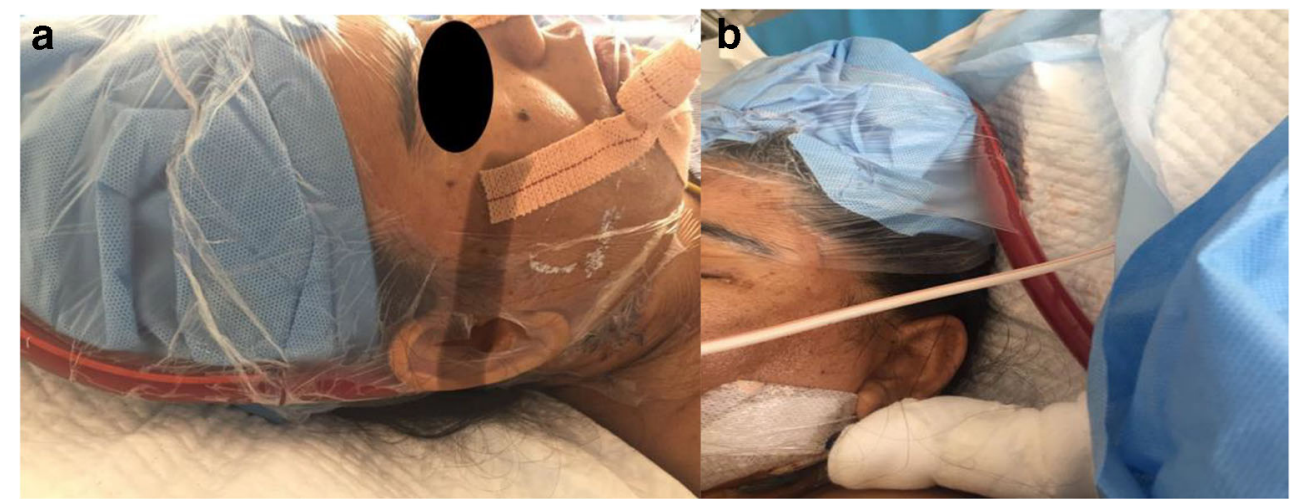




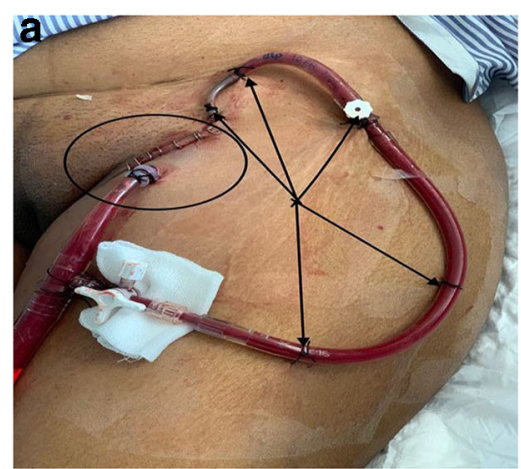

Fig. 3 a Femoral cannulation for VA ECMO. Return cannula in the femoral artery by the semi-open technique shown by the circle. The distal reperfusion cannula securely sutured in a loop at several points as shown by the arrows to make it safe to ambulate patients. b The cannulas are anchored with sutures and transparent tape along the entire length of the

Once ECMO goals are met, after the first $24 \mathrm{~h}$, the aim is a sedation vacation. It would be preferable to leave an analgesic like fentanyl on flow or use dexmedetomidine infusion (if the haemodynamics permit) to ease a patient into conscious sedation. Patients should be evaluated and oriented to time and place once awake. All interventions must be explained to the patient when with reduced sedation, the patient awakens.

Awake ECMO (VA or VV) without mechanical ventilatory support is best initiated early prior to the onset of combined cardiorespiratory insufficiency. Insertion of cannulae in ICU with minimal sedation and minimally invasive techniques is ideal. These patients will benefit from total intravenous anaesthesia (TIVA) or conscious sedation at initiation, followed by anxiolysis and analgesia.

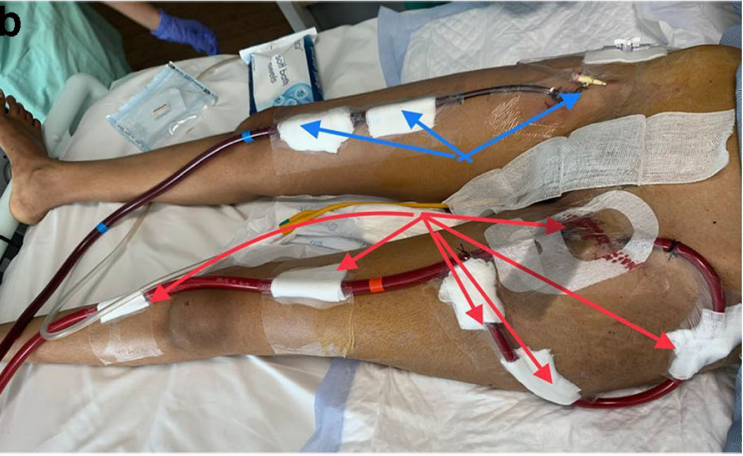

limb at several points as shown by the arrows. The blue arrows mark anchoring of the access cannula which is very long reaching up to the diaphragm. The red arrows mark the suture and tapes of the return cannula and distal reperfusion cannulas which is short reaching only up to the external iliac artery

\section{Individualized planning of airway}

If patients are comfortable with an endotracheal tube (ETT), physiotherapy should be initiated in bed to check baseline muscle power and patient cooperation. Sitting out of bed is very beneficial, but may be uncomfortable or trigger the airway, which in turn may cause flow fluctuations. Ambulating patients with ETT is difficult, as the chances of accidental extubation are higher than of accidental decannulation due to stimulation of the airway. Hence, if one anticipates delayed recovery and longer ECMO run, early individualized planning of airway management (extubation, tracheostomy) is preferred.

Table 3 Ambulation during awake ECMO — sedation and physiotherapy schedule

\begin{tabular}{|c|c|c|c|c|c|}
\hline \multirow{2}{*}{$\begin{array}{l}\text { Strategy for awake } \\
\text { ECMO and } \\
\text { mobilization }\end{array}$} & \multicolumn{5}{|c|}{ Sedation and physiotherapy } \\
\hline & Type & First $24 \mathrm{~h}$ & $24-48 \mathrm{~h}$ & $48-72 \mathrm{~h}$ & $>72 \mathrm{~h}$ \\
\hline \multirow[t]{10}{*}{ Venovenous } & On ventilator & Propofol & Dexmedetomidine & Plan tracheostomy in ARDS & In bed muscle \\
\hline & & Fentanyl & Fentanyl & Plan extubation if bridge to & strengthening \\
\hline & & Atracurium & Midazolam & lung transplant & Mobilization out of bed \\
\hline & & Chest physiotherapy & Passive movements & & if extubated or \\
\hline & & Position change & Postural drainage & & tracheostomy done \\
\hline & & & Muscle strengthening & & \\
\hline & Awake & Dexmedetomidine & Incentive spirometry & Plan mobilization out of bed & Plan mobilization out of \\
\hline & & Fentanyl & and muscle & & bed \\
\hline & & Midazolam & strengthening & & \\
\hline & & Incentive spirometry & exercises & & \\
\hline \multirow[t]{9}{*}{ Venoarterial } & On ventilator & Propofol & Dexmedetomidine & Plan extubation & Plan mobilization out of \\
\hline & & Fentanyl & Fentanyl & Plan tracheostomy if & bed \\
\hline & & Atracurium & Midazolam & extubation not possible and & \\
\hline & & Chest physiotherapy & Passive movements & if bridge to transplant & \\
\hline & & Position change & Postural drainage & & \\
\hline & Awake & Dexmedetomidine & $\begin{array}{l}\text { Muscle strengthening } \\
\text { Incentive spirometry }\end{array}$ & Plan mobilization out of bed & Plan mobilization out of \\
\hline & 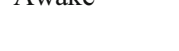 & Fentanyl & and muscle & 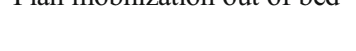 & bed \\
\hline & & Midazolam & strengthening & & \\
\hline & & Incentive spirometry & exercises & & \\
\hline
\end{tabular}




\section{Extubation on ECMO}

The guidelines for the extubation of ECMO patients, as described in the Extracorporeal Life Support Organization (ELSO), are appropriate and straightforward [19] (Fig. 4). ELSO recommends assessing readiness for extubation by the absence of multiorgan failure/shock. The patient should be awake and cooperative enough to at least maintain the airway and not pull out the lines. The patient should have an acceptable arterial blood gas on minimal ventilator settings. Once the patients meet readiness criteria, patients are extubated and placed on non-rebreather masks/high flow nasal cannula (HFNC)/non-invasive ventilation (NIV).

\section{Tracheostomy on ECMO}

Some patients may display agitation and ventilator dyssynchrony on ETT. If the sedation requirement for comfort with ETT is high, early tracheostomy may be a better option for maintaining awake ECMO.

The advantage of tracheostomy over the ETT is the reduction in airway resistance and sedation requirement. It helps with better respiratory protection and more effective bronchopulmonary lavage. The patient, after tracheostomy, can be fed orally and mobilized out of bed safely. The disadvantages are bleeding risk, technical difficulty due to neck cannulae, and the need to stop anticoagulation.
The tracheostomy is by either percutaneous or surgical technique (depending on available expertise and equipment). In VV ECMO patients, as the ECMO runs are longer and the ETT has been in situ for a longer duration, it is best to start considering tracheostomy early [20-22]. In VA ECMO, tracheostomy is done, if one anticipates a prolonged ECMO run, mainly when the respiratory failure is worse than cardiac failure, or it is a bridge to heart transplant.

\section{Physiotherapy and rehabilitation on ECMO (Fig. 5)}

Each ECMO patient has differing needs; therefore, there cannot be a set protocol. A detailed plan has to be made daily, depending on the patient factors such as sedation level, investigations, inotropes, ventilator, and ECMO flow requirements. Physiotherapy in these patients is a team effort, requiring the availability of skilled, trained personnel to plan and safely conduct the physiotherapy. Any intervention requires a careful risk-benefit assessment. Hence, training of the team in the basics of ECMO and cautious mobilization is most important.

\section{Advantages of physiotherapy and rehabilitation}

Respiratory physiotherapy helps to decrease VAP, improve static lung compliance, enhance sputum clearance, and reduce

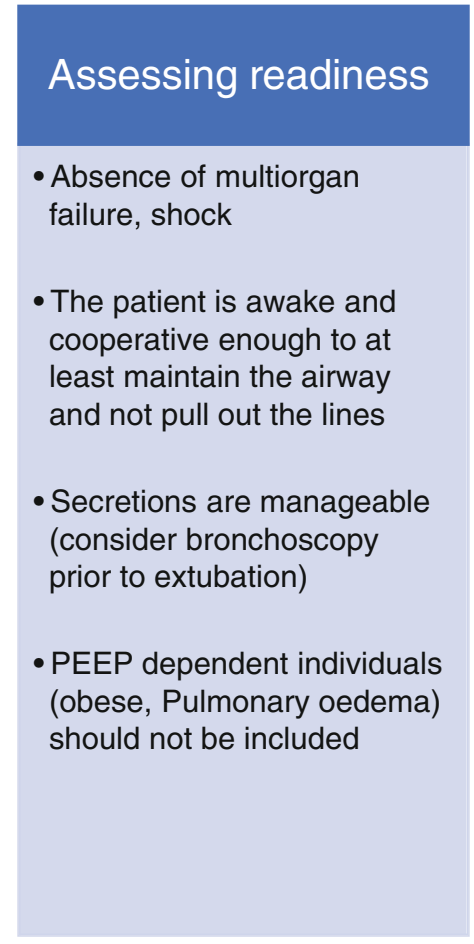

Fig. 4 ELSO recommendations for extubation [19]

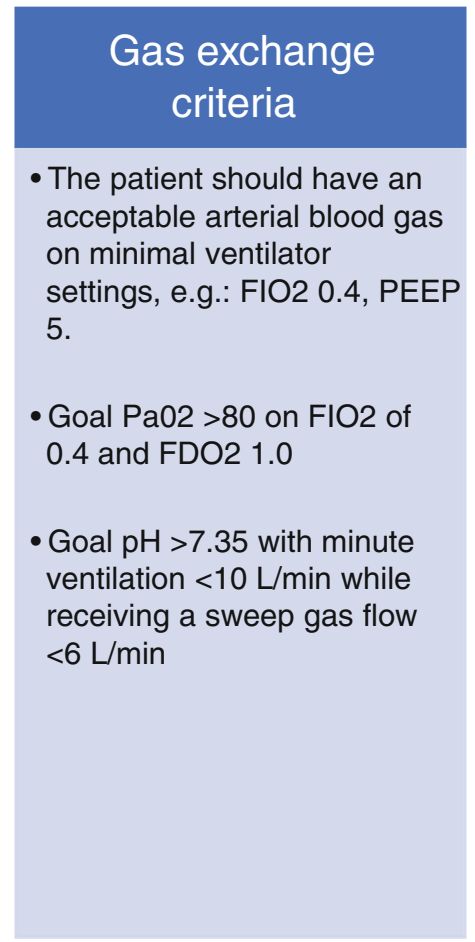

Extubation
- Take an informed consent
from kin
- Perform chest physio and
suctioning
- Prepare supplemental
Oxygen
- Consider extubating to non
rebreather mask / HFNC /
NIV
- Keep emergency intubation
equipment ready for failure
- Check ABG and adjust
sweep post extubation.


atelectasis. Muscle-building exercise plans with early mobilization help in rapid recovery by the prevention of critical illness polyneuropathy. Muscle wasting, which occurs early and rapidly during the first week of illness, can also be prevented and reversed [23]. Awake patients, when engaged in physiotherapy, have an improved psyche due to involvement in goal setting and attainment. Physiotherapy planning depends on sedation levels, oxygen requirements, muscle power, patient cooperation, cannula sites, and team availability (Table 3 ).

\section{Team}

Planning, monitoring, and troubleshooting clinical situations require a specialized team of skilled personnel. The team comprises an intensivist, a bedside nurse, an extra nurse during mobilization, an expert physiotherapist with an assistant, a respiratory therapist, and a perfusionist. Each member has a defined role and the right to stop the activity, if any risk is noticed (Table 4). Dangers while mobilizing out of bed need to be anticipated and handled appropriately (Table 5). The patient should be monitored post mobilization for delayed adverse effects such as displacement of cannulae, bleeding, and fatigue.

\section{How we do it}

As an evolving ECMO program in a lower-middle-income group country, we endeavoured to reduce the duration of ECMO and thus make it cost-effective. We evaluated all factors that hasten recovery and reduce morbidity. The timing of ECMO initiation, length of use of NMBAs, early physiotherapy, and mobilization were the prime factors responsible that made a significant difference. As there were many delays in arranging logistics and obtaining family consent for ECMO, we initiated early counselling for ECMO. Families were updated and given the option and knowledge about ECMO, when patients were undergoing a trial of conventional methods, including prone ventilation [24]. Early counselling helped immensely as the time from advice to decision-making was reduced. We extended training to physiotherapists, respiratory therapists, and nurses every 6 months with mock drills to enable them to be confident with the care of ECMO patients. Finally, we evolved a sedation plan which aimed at conscious sedation without the use of NMBAs $[25,26]$ and synchronized it with a stepwise approach to physical and respiratory therapy (Table 3 ). This titrated sedation and physiotherapy planning helped overcome any delay in rehabilitation during the ECMO run.

In our unit, ARDS and acute respiratory failure received VV ECMO as a treatment option if haemodynamically stable.
Fig. 5 Physiotherapy planning algorithm as per the patient's sedation levels and muscle strength. Our experience of physiotherapy as per this algorithm is shown in Video 1
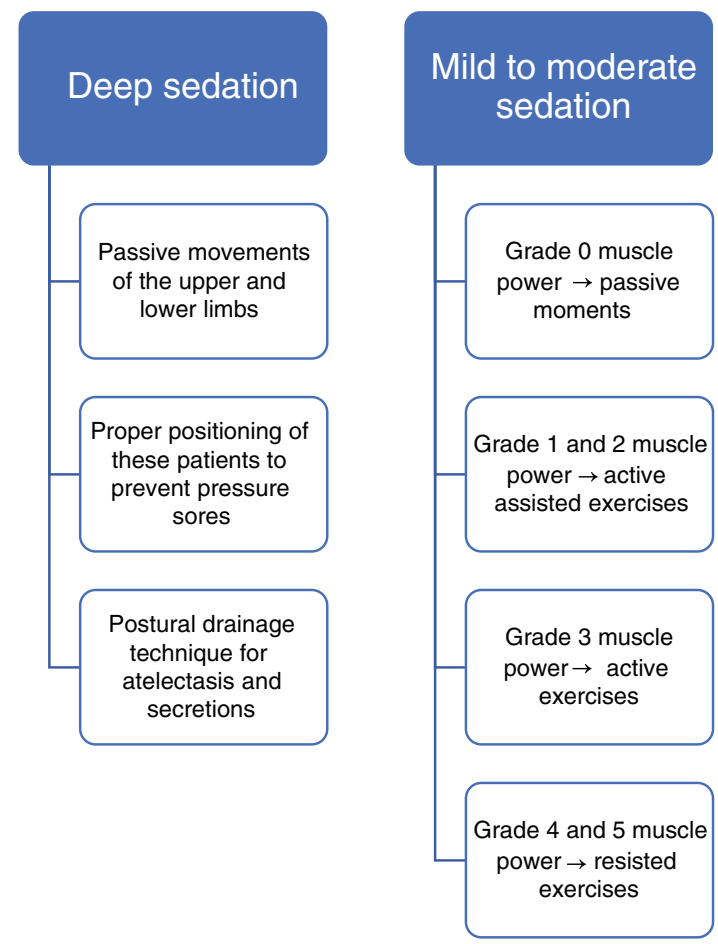

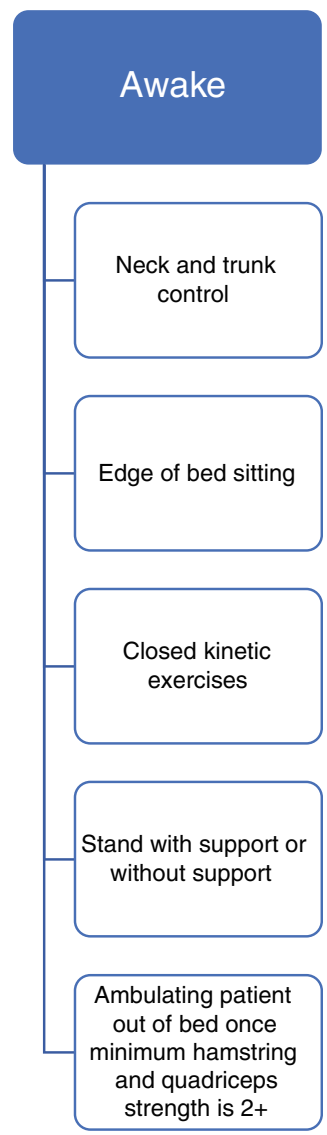


Table 4 Ambulation during awake ECMO — team members and their roles

\begin{tabular}{|c|c|c|c|c|c|c|c|c|c|c|}
\hline \multirow[b]{2}{*}{ Activity } & \multicolumn{2}{|c|}{$\begin{array}{l}\text { Intensivist/ } \\
\text { (team/team leader) }\end{array}$} & \multicolumn{2}{|c|}{$\begin{array}{l}\text { Physiotherapist } \\
\text { Team/team leader }\end{array}$} & \multicolumn{2}{|l|}{ Nursing } & \multicolumn{2}{|l|}{ Perfusionist } & \multicolumn{2}{|c|}{ Respiratory therapist } \\
\hline & Role & No. & Role & No. & Role & No. & Role & No. & Role & No. \\
\hline $\begin{array}{l}\text { - Passive movements of the upper } \\
\text { and lower limbs }\end{array}$ & $\begin{array}{l}\text { Planning by } \\
\text { team leader }\end{array}$ & 1 & $\begin{array}{l}\text { Planning by } \\
\text { team leader }\end{array}$ & 1 & Logistics & 1 & Nil & Nil & Nil & Nil \\
\hline $\begin{array}{l}\text { - Proper positioning pressure sores } \\
\text { - Proper positioning pressure sores }\end{array}$ & $\begin{array}{l}\text { Monitoring } \\
\text { Assisting }\end{array}$ & 1 & Execution & $1 / 2$ & $\begin{array}{l}\text { Monitoring } \\
\text { Assisting }\end{array}$ & $1 / 2$ & Nil & Nil & Nil & Nil \\
\hline $\begin{array}{l}\text { Postural drainage technique for } \\
\text { atelectasis and secretions }\end{array}$ & $\begin{array}{l}\text { Planning } \\
\text { Monitoring }\end{array}$ & 1 & Execution & 1 & Monitoring & 1 & Nil & Nil & $\begin{array}{l}\text { Ventilator } \\
\text { changes } \\
\text { Suctioning } \\
\text { Recruitment }\end{array}$ & 1 \\
\hline Muscle strengthening exercises $0-2$ & Nil & Nil & $\begin{array}{l}\text { Planning } \\
\text { Execution }\end{array}$ & 1 & Monitoring & 1 & Nil & Nil & Nil & Nil \\
\hline Muscle strengthening exercises $2+$ & $\begin{array}{l}\text { Planning } \\
\text { Monitoring }\end{array}$ & 1 & $\begin{array}{l}\text { Planning } \\
\text { Execution }\end{array}$ & 2 & Monitoring & 1 & Nil & Nil & Nil & Nil \\
\hline $\begin{array}{l}\text { Neck and trunk control } \\
\text { Closed kinetic exercises }\end{array}$ & $\begin{array}{l}\text { Planning } \\
\text { Monitoring }\end{array}$ & 1 & $\begin{array}{l}\text { Planning } \\
\text { Execution }\end{array}$ & 2 & Monitoring & 1 & Nil & Nil & Nil & Nil \\
\hline $\begin{array}{l}\text { Assisted to stand with support or } \\
\text { without support }\end{array}$ & $\begin{array}{l}\text { Planning } \\
\text { Monitoring }\end{array}$ & 1 & $\begin{array}{l}\text { Planning } \\
\text { Execution }\end{array}$ & 2 & $\begin{array}{l}\text { Monitoring } \\
\text { Assisting }\end{array}$ & 2 & $\begin{array}{l}\text { Watch the machine } \\
\text { and tubing }\end{array}$ & 1 & $\begin{array}{l}\text { Oxygen therapy } \\
\text { planning } \\
\text { Monitoring }\end{array}$ & 1 \\
\hline Ambulation out of bed & $\begin{array}{l}\text { Planning } \\
\text { Monitoring }\end{array}$ & 1 & $\begin{array}{l}\text { Planning } \\
\text { Execution }\end{array}$ & 2 & $\begin{array}{l}\text { Monitoring } \\
\text { Assisting }\end{array}$ & 2 & $\begin{array}{l}\text { Watch the machine } \\
\text { and tubing }\end{array}$ & 1 & $\begin{array}{l}\text { Oxygen therapy } \\
\text { planning } \\
\text { Monitoring }\end{array}$ & 1 \\
\hline
\end{tabular}

VA ECMO was an option for indications such as cardiotoxic drug/pesticide toxicity, arrhythmias, viral myocarditis, or septic shock. The ARDS patients initiated on VV ECMO were woken on ETT after $24 \mathrm{~h}$ (after achieving the target goals of oxygenation). They received passive and active musclebuilding exercises (Fig. 5 and Video 1). Chest physiotherapy was also initiated immediately after ECMO initiation, after confirming the cannula positions. We have not attempted any extubation on ECMO, but prefer early tracheostomy. Our preferred mode is bilevel ventilation (2 levels of continuous positive airway pressure that allows a mixture of spontaneous and ventilator-mandated breaths) to allow optimal
PEEP and comfort in a spontaneously breathing awake patient.

All patients were maintained in an almost upright position in bed (Fowler's position as tolerated). Upright posture, periodic lateral position, mobilization, and sitting out of bed, after early tracheostomy, were our mobilization algorithm. An optimal patient position improves lung compliance, decreases $\mathrm{V} /$ Q mismatch, and encourages loosening of the secretions. Prone ventilation on ECMO requires deeper sedation and even NMBAs, which would delay awakening the patient; hence, we did not use the prone position for ECMO patients routinely. The cannulation preferably used was a femoral vein to the

Table 5 Ambulation during awake ECMO — role of individual team members in mitigating dangers

\begin{tabular}{|c|c|c|}
\hline Potential danger & Precautions & Team responsibility \\
\hline Haemodynamic instability & Emergency drugs and infusions should be drawn up and ready & An Intensivist and a nurse should monitor \\
\hline Desaturation & $\begin{array}{l}\text { - Depending on lung condition and cause of desaturation } \\
\text { - Flow fluctuations due to cough, changes in cardiac output }\end{array}$ & $\begin{array}{l}\text { - Monitoring and troubleshooting by ECMO specialists } \\
\text { - Oxygen needs and cylinder circuit ventilator to be } \\
\text { arranged by a respiratory therapist }\end{array}$ \\
\hline Dislodgement of cannulas & $\begin{array}{l}\text { - Should be well-secured and watched at all times } \\
\text { - Preferably an x-ray before to be sure of the placement }\end{array}$ & $\begin{array}{l}\text { Monitored for drag, by the assigned person } \\
\text { (nurse/perfusionist/intensivist) }\end{array}$ \\
\hline Pain discomfort & Appropriate analgesia before activity & Ordered by the intensivist \\
\hline Machine malfunction & $\begin{array}{l}\text { - Check connections } \\
\text { - Check battery } \\
\text { - Check oxygen cylinder for sweep gas and reconnect to } \\
\text { mains after mobilization } \\
\text { - Disconnect and reconnect the heater unit for the activity }\end{array}$ & $\begin{array}{l}\text { An intensivist nurse and perfusionist with checklist } \\
\text { similar to one used for transporting patient } \\
\text { anywhere on ECMO }\end{array}$ \\
\hline
\end{tabular}


right IJV. We were comfortable walking patients and sitting them in a chair with femoral cannulae and tracheostomy tubes. Our double-lumen cannula use in one of our patient's resulted in limited mobilization out of bed only because the length of tubing was inadequate (Video 1) (all exercises in the video were performed with planning by experts).

Our awake ECMO experience was in patients who presented with cardiogenic shock after aluminium phosphide poisoning [27]. The challenge faced was the initiation of awake ECMO on a haemodynamically unstable patient (without intubation), as sedation causes blunting of adrenaline drive and respiratory drive. We used a combination of sedative analgesic agents as TIVA, keeping the cannulation time for initiation of ECMO short. We cannulated the patients using a semi-open technique for insertion of return cannula and distal reperfusion cannula in the femoral artery. The femoral vein for access was secured using ultrasound and transthoracic echocardiography (TTE)-guided Seldinger's technique. These patients were managed with NIV at ECMO initiation, nasal prongs during the day, and HFNC/NIV at night as appropriate. They practiced incentive spirometry, muscle-building exercises, and mobilization out of bed as tolerated (Video 1). Attention to psychological counselling, constant interaction with family and friends, and utilization of recreational activities aided in early recovery and acceptance of awake ECMO.

\section{Conclusion}

ECMO patients are the sickest of critical care patients. Hence, the aim of the ECMO program should not only be survival, but also getting back to a meaningful life with few long-term sequelae. All patients should be considered for awakening on ECMO as soon as possible to hasten recovery with early physical rehabilitation. Careful patient selection and planning are essential for awake ECMO and are preferable when bridging to organ transplant to prevent infections and muscle deconditioning for better outcomes. Better oral nutrition, lesser ICU psychosis, and post-ICU syndrome result in a shorter stay in the ward after ICU discharge and thus reduced burden on the patient and family. Patients on ECMO should be planned for physiotherapy daily with frequent re-evaluation and goal setting. There is strong evidence that this results in a speedy recovery, decreases the length of hospital stay, and improves the level of independence of the patient at hospital discharge.

Supplementary Information The online version contains supplementary material available at https://doi.org/10.1007/s12055-020-01075-z.

Acknowledgements Dr. Ramanathan K R, CTICU fellowship program Director, NUH Singapore for expert inputs and critical evaluation.
Dr. Rajavardhan $\mathrm{R}$ - Consultant Critical care medicine, Manipal Hospital for inputs and editing of the content.

Dr. M N Chidananda Swamy - Consultant Intensivist, Neurocritical Care, Brunei Neuroscience Stroke and Rehabilitation Center Unit, Past Hon Secretary ISA Karnataka State \& Bangalore City Branch, Past President ISA Bangalore City Branch, for critical evaluation and expert editing of the content.

Authors' contribution Dr. Jumana Haji is the main author and has scripted the document.

Mr. Sanyam Mehra has given inputs on the physical therapy and been a part of all the planning and execution of the exercises conducted in the attached video.

Dr. Prakash Doraiswamy has given inputs in critical care management aspects.

Funding Nil.

\section{Compliance with ethical standards}

Conflict of interest The authors declare that they have no conflicts of interest.

Ethical committee approval Ethical approval was waived by the local Ethics Committee of Aster CMI Hospital in view of the retrospective nature of the data presented in pre-COVID times, and all the procedures being performed were part of the routine care and care being taken to conceal patient identity.

\section{References}

1. Schweickert WD, Pohlman MC, Pohlman AS, et al. Early physical and occupational therapy in mechanically ventilated, critically ill patients: a randomised controlled trial. Lancet. 2009;373:1874-82.

2. Parker A, Sricharoenchai T, Needham DM. Early rehabilitation in the intensive care unit: preventing impairment of physical and mental health impairments. Curr Phys Med Rehabil Rep. 2013;1:307-14.

3. Langer T, Santini A, Bottino N, et al. "Awake" extracorporeal membrane oxygenation (ECMO): pathophysiology, technical considerations, and clinical pioneering. Crit Care. 2016;20:150.

4. Langer T, Vecchi V, Belenkiy S, et al. Extracorporeal gas exchange and spontaneous breathing for the treatment of acute respiratory distress syndrome. Crit Care Med. 2014;42:e211-20.

5. Schmidt M, Pham T, Arcadipane A, et al. Mechanical ventilation management during extracorporeal membrane oxygenation for acute respiratory distress syndrome. An international multicenter prospective cohort. Am J Respir Crit Care Med. 2019;200:100212.

6. Morris AH, Wallace CJ, Menlove RL, et al. Randomized clinical trial of pressure-controlled inverse ratio ventilation and extracorporeal $\mathrm{CO} 2$ removal for adult respiratory distress syndrome. Am J Respir Crit Care Med. 1994;149:295-305.

7. Kurihara C, Walter JM, Singer BD, et al. Extracorporeal membrane oxygenation can successfully support patients with severe acute respiratory distress syndrome in lieu of mechanical ventilation. Crit Care Med. 2018;46:e1070-3.

8. Chacko CJ, Goyal S, Yusuff H. Awake extracorporeal membrane oxygenation patients expanding the horizons. J Thorac Dis. 2018;10:S2215-6.

9. Stahl K, Seeliger B, Hoeper MM, David S. "Better be awake"-a role for awake extracorporeal membrane oxygenation in acute 
respiratory distress syndrome due to Pneumocystis pneumonia. Crit Care. 2019;23:418.

10. Yeo HJ, Cho WH, Kim D. Awake extracorporeal membrane oxygenation in patients with severe postoperative acute respiratory distress syndrome. J Thorac Dis. 2016;8:37-42.

11. Deng L, Xia Q, Chi C, Hu G. Awake veno-arterial extracorporeal membrane oxygenation in patients with perioperative period acute heart failure in cardiac surgery. J Thorac Dis. 2020;12:2179-87.

12. Mori M, McCloskey G, Geirsson AD, et al. Improving outcomes in INTERMACS category 1 patients with pre-LVAD, awake venousarterial extracorporeal membrane oxygenation support. ASAIO J. 2019;65:819-26.

13. Buratto E, Tarzia V, Bottio T, et al. Extracorporeal membrane oxygenation as a bridge to life for refractory cardiogenic shock. Heart, Lung Circ. 2012;21:S278.

14. Xia J, Gu S, Li M, et al. Spontaneous breathing in patients with severe acute respiratory distress syndrome receiving prolonged extracorporeal membrane oxygenation. BMC Pulm Med. 2019;19: 237.

15. Biscotti M, Gannon WD, Agerstrand C, et al. Awake extracorporeal membrane oxygenation as bridge to lung transplantation: a 9-year experience. Ann Thorac Surg. 2017;104:412-9.

16. Abrams D, Garan AR, Brodie D. Awake and fully mobile patients on cardiac extracorporeal life support. Ann Cardiothorac Surg. 2019;8:44-53.

17. Sorokin V, MacLaren G, Vidanapathirana PC, Delnoij T, Lorusso $\mathrm{R}$. Choosing the appropriate configuration and cannulation strategies for extracorporeal membrane oxygenation: the potential dynamic process of organ support and importance of hybrid modes. Eur J Heart Fail. 2017;19:75-83.

18. deBacker J, Tamberg E, Munshi L, Burry L, Fan E, Mehta S. Sedation practice in extracorporeal membrane oxygenation-treated patients with acute respiratory distress syndrome. A retrospective study. ASAIO J. 2018;64:544-51.
19. Elso.org. 2020 https://www.elso.org/Portals/0/Files/ELSO_ ExtubationGuidelines_May2015.pdf

20. Boulos FM, Raithel M, Brigante F, et al. Time to tracheostomy: early tracheostomy may decrease the duration of extracorporeal membrane oxygenation support in patients with acute respiratory distress syndrome. J Am Coll Surg. 2017;225:S65.

21. Swol J, Strauch JT, Schildhauer TA. Tracheostomy as a bridge to spontaneous breathing and awake-ECMO in non-transplant surgical patients. Eur J Heart Fail. 2017;19:120-3.

22. Salna M, Tipograf $Y$, Liou $P$, et al. Tracheostomy is safe during extracorporeal membrane oxygenation support. ASAIO J. 2020;66: 652-6.

23. Puthucheary ZA, Rawal J, McPhail M, et al. Acute skeletal muscle wasting in critical illness. JAMA. 2013;310:1591-600.

24. Combes A, Hajage D, Capellier G, et al. Extracorporeal membrane oxygenation for severe acute respiratory distress syndrome. N Engl J Med. 2018;378:1965-75.

25. Anton-Martin P, Modem V, Taylor D, Potter D, Darnell-Bowens C. A retrospective study of sedation and analgesic requirements of pediatric patients on extracorporeal membrane oxygenation (ECMO) from a single-center experience. Perfusion. 2017;32: 183-91.

26. Taylor MA, Maldonado Y. Anesthetic management of patients on ECMO. In: Firstenberg MS, editor. Extracorporeal membrane oxygenation: advances in therapy. InTech; 2016. https://doi.org/10. 5772/63309

27. Mohan B, Singh B, Gupta V, et al. Outcome of patients supported by extracorporeal membrane oxygenation for aluminum phosphide poisoning: an observational study. Indian Heart J. 2016;68:295301 .

Publisher's note Springer Nature remains neutral with regard to jurisdictional claims in published maps and institutional affiliations. 